\title{
环保节能理念在建筑给排水设计中的应用
}

\author{
陈永亮* \\ 山东澳大环保水处理有限公司, 山东 250022
}

\begin{abstract}
摘要：建筑行业是随着我国现代化建设不断开展而迅速发展的行业, 该行业对于我国有着重要意义, 所以近几年来我国建筑行业的 发展愈发迅速, 尤其是建筑的设计和施工发生了很大的变化, 建筑的形式功能也愈发完善, 给人们提供了更多便利。但建筑行业在发展中 的高能耗问题也十分突出，所以我国在实行了可持续发展战略以后，就提出了环保节能的理念，对建筑的设计和施工提出了更高的要求。 在建筑的设计工作中, 给排水设计是其中必不可少的设计内容, 给排水设计对于人们正常生活的影响是很大的, 而其在运行的过程中也容 易造成比较大的浪费和损失, 所以将环保节能理念应用于其中是十分必要的。本文就对环保节能理念在建筑给排水设计中的相关应用进行 具体探讨。
\end{abstract}

关键词：环保节能理念；建筑；给排水设计；应用

\section{Application of Environmental Protection and Energy Saving Concept in the Design of Building Water Supply and Drainage}

\author{
Yong-Liang Chen * \\ Shandong Australian Environment Protection Water Treatment Co., Ltd., Jinan 250022, Shandong, China
}

\begin{abstract}
The construction industry is an industry that develops rapidly with the continuous development of China's modernization. This industry is of great significance to China. Therefore, the development of China's construction industry has become more and more rapid in recent years, especially the design and construction of buildings have changed. The form and function of the building have become more and more complete, providing people with more convenience. However, the problem of high energy consumption in the development of the construction industry is also very prominent. So after implementing the sustainable development strategy, China has proposed the concept of environmental protection and energy saving, and put forward higher requirements for the design and construction of buildings. In the design of buildings, water supply and drainage design is an indispensable design content. Water supply and drainage design has a great impact on people's normal life, and it is easy to cause greater waste and loss in the process of operation. Therefore, it is necessary to apply the concept of environmental protection and energy saving. This article specifically discusses the related applications of environmental protection and energy saving concepts in building water supply and drainage design.
\end{abstract}

Keywords: Environmental protection and energy saving concept; building; water supply and drainage design; application

一、引言

自从我国实行了可持续发展战略以来, 环保节能理念就成为各行各业发展的新型理念, 对各个行业的发展产生了重要影响。我国建筑行 业自从发展以来, 高能耗和较高的资源浪费问题就成为制约其发展的重要问题, 所以在实行可持续发展战略以后, 建筑行业也贯彻了环保节 能的理念, 利用环保节能理念进行建筑的设计和施工, 这对于建筑行业的可持续发展十分重要。在建筑的众多结构和设计中, 给排水设计是 十分基础的，对于人们的生活影响也很大，所以在现代建筑给排水设计工作中，施工单位需要加强环保节能理念在其中的有效应用。

二、环保节能理念在建筑给排水设计中应用的必要性

自从我国改革开放以来, 经济社会的发展就迈人了新的阶段, 各行各业都获得了更多地发展空间, 发展速度也在不断加快, 尤其是其中 的建筑行业, 随着我国社会化进程的开展, 其发展也更加迅猛, 这固然促进了我国的经济建设和社会发展, 但是与此同时也带来严重的生 态和环境问题。

能源资源浪费和生态环境污染已经成为当前各国都面临的重要发展问题, 能源资源的利用率低下, 对生态环境的污染也比较严重, 这不 利于经济社会的健康发展。

环保节能理念是我国提出可持续发展战略以后出现的一种新的理念, 这种理念主要集中于环保和节能, 提高能源资源的利用率, 加强环 境保护，减轻人类活动对生态环境造成的影响，这为行业的发展指明了新的方向。

建筑行业是近几年来推动我国经济社会发展的重点行业，而在建筑的设计施工和使用过程中，都会消耗大量的能源和资源，对生态环境 的影响也比较大，所以我国在开展可持续发展战略时，对建筑行业进行改造就是其中的重点。

在建筑的给排水设计工作中, 水资源和系统运行的能源是建筑成本的重要构成, 如果能够将环保节能理念应用于其中, 提高水资源和能

*通讯作者: 陈永亮, 1982 年 10 月, 男, 汉族, 山东无棣县人, 现任山东澳大环保水处理有限公司工程技术部经理、给排水中级工程师, 大学本科。研究方向：建筑给排水专业。 
源的利用率，做好资源节约，就可以真正达到节能环保的效果，降低建筑使用的成本，这对于建筑行业的可持续发展是十分有利的。

\section{三、设计建筑给排水系统的作用}

(一) 设置自动排气阀

建筑的给排水系统与排气装置是相辅相成的, 二者必须要同时存在, 才能够保证给排水系统各项功能的正常运转, 所以现代建筑的给排 水系统中也会设置自动排气阀, 这种气阀能够对给排水系统的流量进行有效控制, 保证供水的稳定性, 同时浪费的情况也相对较轻。

(二) 增设户外阀门

建筑的给排水系统并不是一个完全自动化的系统, 其在运行的过程中可能会出现各种问题, 所以在进行给排水设计时, 就需要设置一个 人工控制的途径, 比如增设户外阀门（如图1），这样一旦建筑的给排水系统出现了问题，还能够从外部通过人工操作的方式进行解决。

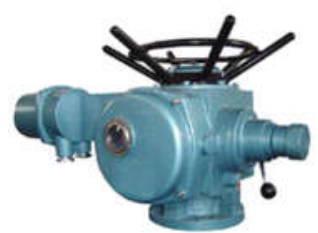

图1 户外阀门

（三）设计户外阀门安装方式

户外阀门在安装时安装的方式需要谨慎选择, 因为户外划门的种类不一致, 而不同的阀门需要采用不同的安装方法, 才能够使其与整个 建筑给排水系统相适应，稳定起其用。

( 四) 设计水弯和地漏

在建筑内部的排水口处通常都会设置地漏, 地漏的主要作用是防止排水管道中的污水回返, 对于保持地面整洁和促进排水是有着积极作 用的, 而只要在污水收集的过程中达到规定存水量, 相关参数也相对合理, 就可以使排水系统正常运行, 只是具体的安装方法和安装位置 还需要进一步探讨。

(五) 排水管管径设计

建筑给排水系统在运行的过程中, 污水的排放会影响到建筑内部的环境, 但是污水中通常还有很多的杂质和污染物, 这些污染物的存在 可能会导致排水管道堵塞。所以在建筑的给排水设计工作中, 设计人员需要根据该建筑的使用要求和当前的使用情况, 对对排水管道的管 径进行设计。

\section{四、环保节能理念在建筑给排水设计中应用的现状}

(一) 给水管道压力不足

建筑的给排水设计, 包括建筑的给水设计和排水设计, 而给水设计对于人们的正常用水会产生直接影响, 所以就成为建筑给排水设计的 重点。

在给水设计工作中，给水管道凭借其内部的压力进行水资源的传输，所以给水管道的压力在一定程度上会影响到水资源的正常供应。

可是在实际的施工工作中可以发现, 很多建筑的给水管道由于各种因素的影响, 管道的压力都明显不足, 而这一问题的存在会给用户的 正常用水带来很大不便 ${ }^{[1]}$ 。

(二) 废水回收利用不到位

建筑给排水设计中的资源主要指的是水资源, 所以环保节能理念在其中的应用也主要是提高水资源的利用率, 而这就需要进行废水的有 效回收利用, 减少水资源的浪费。建筑在正常的使用过程中会产生大量废水, 其中很多废水是可以经过回收再利用的, 这是提高水资源利 用率的有效方式。但是很多施工单位在废水回收方面都存在着不足, 技术方面相对比较落后, 很多先进的设备和系统也无法应用于其中, 只能进行一些简单的废水过滤和随机利用, 废水的处理效率并不高 ${ }^{[2]}$ 。

(三) 施工材料质量问题

给排水系统是建筑的重要基础系统, 给排水系统的施工质量对于人们正常用水和生活都会产生直接影响, 而这其中, 施工材料的质量 又是影响给排水系统施工质量的重要因素, 所以在建筑给排水系统设计中, 也需要加强对施工材料质量的管理。但是在实际施工中可以发 现, 很多施工单位对施工材料质量的控制并不到位, 尤其是在环保节能理念提出之后, 很多施工单位可能片面追求节能环保, 而忽视了系 统本身的质量和功能，导致建筑给排水系统的功能得不到有效发挥 ${ }^{[3]}$ 。

\section{五、环保节能理念在建筑给排水设计中的应用措施}

(一) 合理利用太阳能

建筑给排水系统在运行的过程中也需要消耗大量的能源, 这里的能源消耗主要用于水的加热, 用于循环热水供应, 所以在环保节能理念 应用的过程中，还需要对其能源消耗进行优化设计，利用太阳能来代替传统能源，以减轻系统运行对环境造成的负担。

太阳能与传统能源相比, 其本身具有清洁性和环保性的优势, 所以施工单位在进行建筑给排水设计时, 可以在建筑的顶层或高层设置太 阳能建设点, 用于太阳能的收集和存储, 这样在后期建筑给排水系统应用过程中, 如果出现低温天气或其他气象问题, 就可以利用太阳能代 替传统能源进行加热, 进行热水的循环供应 ${ }^{[4]}$ 。在利用太阳能时, 主要使用的是太阳能集热板, 所以在使用中, 可以直接将其安装在阳台、 景观或道路旁，如果必要也可以将太阳能与其他的能源结合在一起。无论是哪种方式，都能够有效提高建筑给排水系统应用的节能效果。 


\section{(二) 完善给水管道压强}

在建筑的给排水设计中, 给水系统的正常运行需要给水管道内的压强适当, 能够保证水资源的正常供应, 这样就可以保证充足的水资源 供应, 从而防止不必要的浪费。但是随着我国建筑行业的不断发展, 高层建筑和超高层建筑也在不断增加, 在这种建筑内给水管道的压强经 常会不足, 这时就需要加强对水压的调控, 必要时可以购买辅助设备 ${ }^{[5]}$ 。

(三) 改善循环供应热水系统

在建筑的给排水系统中, 循环供应热水系统也是其中的重要部分, 该系统主要是对用户进行热水的供应, 对人们的日常生活会带来很大 影响, 但是在该系统运行的过程中, 也很容易出现不必要的能源资源浪费。用户在使用热水时可以发现, 阀门都会先流出冷水, 然后逐渐 升温, 最终流出热水, 也就是说需要先将冷水放掉一部分才能够正常使用热水, 这本身就是一种水资源的浪费 ${ }^{[6]}$ 。

所以在环保节能理念应用的过程中, 设计人员需要对循环供应热水系统进行适当的优化和改进, 最好采用新型的集中热水循环供应系 统，对系统运行的相关标准和性能进行了解及控制，这也可以达到有效的节约效果。

( 四 ) 调控超压出流

前面提到建筑给排水系统在运行时可能会出现给水管道压强不足的情况, 导致无法正常供水, 但是除此之外, 超压出流的问题也是存在 的, 超压出流指的就是管道的压力过大, 所有的给水设施在压力方面都是有着一定标准和要求的, 如果超过了一定压力值, 就会出现超压 出流，这时流出的水量就极大，这同样也会引发不必要的水资源浪费 ${ }^{[7]}$ 。

所以设计人员需要考虑到建筑的高度以及给排水系统的施工要求及相关参数, 根据实际情况对给水管道的压力进行调控, 可以设置减压 阀 ${ }^{[8]}$, 如图2所示。

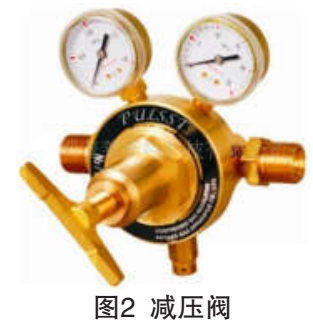

（五）使用优质材料和阀门

施工材料和相关器件的质量, 对于建筑给排水设计的质量和给排水系统的运行质量都会产生直接影响, 而材料的相关性能也直接影响到 该系统运行的环保节能效果。所以设计人员在开展建筑给排水设计工作时, 要尽量使用优质的材料和阀门, 最好使用一些具有节能性或环 保性的材料器具, 用环保节能材料代替传统材料, 对阀门等器件进行改进, 比如选择更加坚固、耐用、防腐蚀和耐高温的材料, 而且这些 材料最好能够回收再利用, 而阀门等器件则要求其具有更强的密封性, 防止出现泄漏 ${ }^{[9]}$ 。

(六) 合理设置水泵参数

建筑给排水系统在应用的过程中势必会使用到水洜和水箱等设施, 尤其是其中的水泵, 对于供水系统的正常运行会产生直接影响, 水洜 的运行效率在一定程度上决定了水资源的供应效率和稳定性。所以在现代建筑的给排水设计工作中, 设计人员为了兼顾环保和应用质量, 可以提前对水泵的应用参数进行调整，使水泵的运作更加清晰。

另外, 为了减少水洜运行过程中的能量损耗, 设计工作中可以引人具有控制功能的水洜, 根据用户的用水需求合理调整其功率, 从而达 到最佳的供水效果，减少不必要的水资源浪费 ${ }^{[10]}$ 。

（七）应用节水节能器具

环保节能理念在建筑给排水设计中的应用主要就体现在了水资源的利用上，努力提高水资源的利用率，减少水资源浪费，而为了达到该 目的, 设计人员可以在设计工作中就应用节水节能器具。目前我国市场上的节水节能器具已经比较多, 种类也比较复杂, 这种器具与传统 的器具相比, 其运行的功率比较低, 对用水量的控制也比较严格, 所以能够有效提高水资源的利用率。比较常见的节水器具, 包括了节水 龙头 (如图3) 节水马桶和节水阀门等。

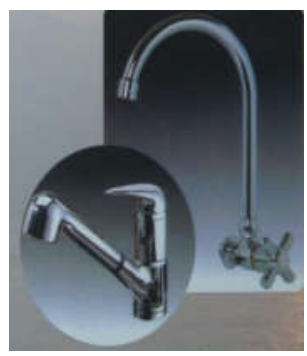

图3 节水龙头

\section{六、结束语}

通过对上文内容的总结, 可以得知, 在建筑的给排水设计工作中, 环保节能理念的应用能够提高能源资源的利用率, 起到有效地节水和 
环保效果，对于我国建筑行业的可持续发展是十分有利的。

建筑给排水设计工作是一个十分系统且复杂的工作, 其内容比较多, 所以想要将环保节能理念应用于其中, 就需要对其每个环节进行有 效控制。但是很多建筑施工单位在进行建筑给排水设计工作中, 对于环保节能理念的应用还并不到位, 经常会出现给水管道压力不足、废 水回收利用不足以及施工材料质量问题等。

针对这些问题, 要求建筑工程的施工单位在开展给排水设计工作室需要将环保节能理念有效贯彻其中, 加强给排水系统中相关管道、 参数以及材料等的有效控制, 采取有效的节水措施和节能措施, 提高给排水设计的环保节能效果。

\section{参考文献:}

[1]黄海萍.建筑给排水设计中环保节能理念应用研究[J].城市住宅, 2019,26(10):163-164.

[2]刘文飞.环保节能理念在建筑给排水设计中的应用[J].建材与装饰, 2019(29):89-90.

[3]刘劲成.基于节能环保的建筑给排水设计与应用 [J].中国高新科技, 2019(18):88-90.

[4]胡阔畔.环保节能理念在建筑给排水设计中的应用价值研究[J].居业, 2019(08):71+73.

[5]李倩倩.环保节能理念在建筑给排水设计中的应用 [J].居舍, 2019(18):94+167.

[6]宋英杰.建筑给排水设计中环保节能的应用 [J].建材与装饰, 2019(16):79-80.

[7]张巧慧.试论环保节能理念在建筑给排水设计中的应用 [J]. 江西建材, 2019(05):71-72.

[8] 郭金亮. 环保理念应用于建筑给排水设计中的必要性解析[J].绿色环保建材, 2019(06):82+86.

[9]李容.绿色环保理念在建筑给水排水设计中的应用 [J].建材与装饰, 2019(14):72-73.

[10]曾点.建筑给排水设计中环保节能理念的应用初探[J].建材与装饰, 2019(10):70-71. 